\title{
Atrial septal defect repair after a 10-month treatment with bosentan in a patient with severe pulmonary arterial hypertension: A case report
}

Konrad Hoetzenecker, MD, ${ }^{a}$ Hendrik J. Ankersmit, MD, ${ }^{a}$ Diana Bonderman, MD, ${ }^{b}$ Wolfram Hoetzenecker, MD, PhD, Reinald Seitelberger, MD, ${ }^{a}$ Walter Klepetko, MD, ${ }^{a}$ and Irene M. Lang, MD, ${ }^{b}$ Vienna, Austria, and Tübingen, Germany

Congenital type II atrial septal defect (ASD) is associated with precapillary pulmonary hypertension (PAH) in roughly $10 \%$ of cases. ${ }^{1}$ Principally, closure of the shunt lesion is recommended, and large ASDs must be repaired in early childhood to prevent Eisenmenger's syndrome. Once severe pulmonary hypertension or Eisenmenger's syndrome has developed, ASD closure is problematic due the increased risk of right ventricular failure and pulmonary hypertensive crisis. ${ }^{2}$ At this stage, heart-lung transplantation is the only surgical option. Nonsurgical strategies include supplemental oxygen, digitalis, anticoagulation, and vasodilator treatments.

In contrast to the traditional rule of inoperability of an ASD with severe pulmonary hypertension, single case reports have demonstrated that surgical correction of an ASD is feasible but requires longtime pre- and postoperative treatment with vasodilators. $^{3-5}$

Endothelin receptor antagonists are a new class of vasoactive substances, some of which (eg, bosentan) are orally active. Bosentan has been shown to lower pulmonary artery pressure (PAP) and to induce reverse remodeling of the pulmonary arteries.

We report the case of a patient with type II ASD and severe pulmonary hypertension. Successful surgical closure of the ASD was possible with near-normalized PAPs after 10 months of "conditioning" medication with bosentan.

\section{CLINICAL SUMMARY}

A 71-year-old woman was admitted to hospital because of exercise intolerance and cough. She presented in World Health Organization functional class IV and was given permanent oxygen. Pneumonia was diagnosed and an antibiotic regimen was started. Electrocardiography showed a right bundle branch block with left axis deviation of $-130^{\circ}$. Routine echocardiography revealed severe pulmonary hypertension with a systolic PAP of $89 \mathrm{~mm} \mathrm{Hg}$ and a large type II ASD with a bidirectional shunt. The defect size

\footnotetext{
From the Departments of Cardiothoracic Surgery ${ }^{\mathrm{a}}$ and Cardiology, ${ }^{\mathrm{b}}$ Medical University of Vienna, Vienna, Austria Department of Dermatology, ${ }^{\mathrm{c}}$ Medical University Tübingen, Germany.

Received for publication Nov 11, 2007; revisions received March 3, 2008; accepted for publication March 23, 2008.

Address for reprints: H. J. Ankersmit, MD, Department of Cardiothoracic Surgery, Medical University of Vienna, Währinger Gürtel 18-20, 1090 Vienna, Austria (E-mail: hendrik.ankersmit@meduniwien.ac.at).

J Thorac Cardiovasc Surg 2009;137:760-1

$0022-5223 / \$ 36.00$

Copyright (c) 2009 by The American Association for Thoracic Surgery doi:10.1016/j.jtcvs.2008.03.064
}

was $15 \times 36 \mathrm{~mm}$, too large for interventional closure. Cardiac catheterization confirmed the diagnosis of severe PAH with a pulmonary vascular resistance over 400dynes • $\mathrm{s}$. $\mathrm{cm}^{-5}$, which is the cutoff for shunt closures at our institution, and a nitric oxide nonresponder status ${ }^{6}$ (Table 1). Surgical repair of the type II ASD was deemed impossible because of the degree of PAH with a mean PAP of 54, high B-type natriuretic peptide, and the patient's severe physical limitation. Bosentan therapy to condition the patient toward a later ASD closure was found to be an option by an interdisciplinary consent. Bosentan was started at a dosage of $125 \mathrm{mg} / \mathrm{d}$ (2 $\times 62.5 \mathrm{mg}$ twice a day) and was increased to $250 \mathrm{mg} / \mathrm{d}$ after 1 month. Laboratory parameters were controlled monthly, and no significant elevation of liver enzymes occurred. Ten months after initiation of bosentan, repeat cardiac catheterization revealed significantly reduced pulmonary pressures (Table 1), stimulating a surgical closure of the type II ASD with a Dacron patch. In addition, the patient's tricuspid valve insufficiency was repaired utilizing an Edwards Lifesience (Irvine, Calif) MC3 32-mm ring. The patient was extubated on the first postoperative day; norepinephrine and dobutamine given for cardiac support were stopped 2 days later. During the further postoperative course, recurrent right-sided pleural effusion and a sudden pericardial tamponade had to be tapped. The patient was discharged from the hospital on postoperative day 28 under bosentan treatment $(250 \mathrm{mg} / \mathrm{d})$. Eight months thereafter, the patient was in good clinical condition with mild pulmonary hypertension.

\section{DISCUSSION}

In this case report, we describe significant hemodynamic improvement under bosentan therapy, allowing surgical closure of a type II ASD 10 months after bosentan induction, with good clinical outcome 8 months postoperatively.

Treatment options for elderly patients suffering from pulmonary hypertension are limited. Medical treatment is the standard therapeutic option, as surgical closure of the shunt is associated with an increased postoperative mortality. ${ }^{2}$ The main obstacle for surgical treatment is right ventricular dysfunction/failure in the presence of severe pulmonary hypertension after the surgical intervention. However, several recent case reports have demonstrated that postoperative reduction of PAP significantly reduces the risk of right heart failure, making surgical closure a possible treatment option. $^{3,4}$

Recently, Frost et $\mathrm{al}^{5}$ reported a vasodilatative "conditioning" therapy in a patient with Eisenmenger's syndrome 
TABLE 1. Time course of clinical and hemodynamic parameters

\begin{tabular}{|c|c|c|c|c|}
\hline \multirow[b]{2}{*}{ Parameter } & \multicolumn{2}{|c|}{ Before bosentan initiation } & \multirow[b]{2}{*}{ Before ASD repair } & \multirow{2}{*}{$\begin{array}{c}8 \text { months after ASD } \\
\text { repair } \\
\end{array}$} \\
\hline & Baseline & NO (20 ppm) & & \\
\hline mLAP (mm Hg) & 17 & 17 & 11 & 13 \\
\hline mRAP (mm Hg) & 16 & 16 & 10 & 7 \\
\hline mPAP $(\mathrm{mm} \mathrm{Hg})$ & 54 & 42 & 30 & 35 \\
\hline Pulmonary/systemic flow (L/min) & $9.5 / 3.5$ & $14.0 / 4.3$ & $7.4 / 3.3$ & $5.2 / 5.2$ \\
\hline Arterial saturation $(\%)$ & 91 & 95 & 88 & 95 \\
\hline Pulmonary arterial saturation $(\%)$ & 75 & 84.5 & 77.7 & 62.0 \\
\hline Total pulmonary resistance $\left(\right.$ dynes $\cdot \mathrm{s} \cdot \mathrm{cm}^{-5}$ ) & 460 & 240 & 325 & 538 \\
\hline B-type natriuretic peptide $(\mathrm{pg} / \mathrm{mL})$ & 4675 & & 1104 & 420 \\
\hline 6-min walking distance $(\mathrm{m})$ & 152.2 & & 241.0 & 247.0 \\
\hline
\end{tabular}

$A S D$, Atrial septal defect; $N O$, nitric oxide; $m L A P$, mean left atrial pressure; $m R A P$, mean right atrial pressure; $N D$, not done; $m P A P$, mean pulmonary arterial pressure.

that was initially considered inoperable. The type II ASD in this case could be closed after 4 years of epoprostenol therapy. Eight years after surgical intervention, the patient is clinically stable with near-normal pulmonary pressures. ${ }^{5}$

We now present a similar case treated with bosentan. Bosentan has several advantages compared to epoprostenol. Because it is an oral drug, there are no complications related to intravenous delivery systems, which are common under prostaglandin therapy. Furthermore, adverse side effects of epoprostenol including headache, diarrhea, and rash are avoided. By contrast, the side effect profile of oral bosentan includes elevated liver enzymes in $7 \%$ of cases. Fortunately, no clinically relevant increases of transaminases occurred in our patient during 16 months of follow-up.

In the described case, bosentan was continued because of the 8-month hemodynamic data together with the assumption that a pulmonary vascular disease was present. As the clinical outcome in this elderly patient was excellent, further invasive diagnostic procedures reevaluating bosentan therapy were abandoned.
We conclude that bosentan treatment of a patient with type II ASD and severe pulmonary hypertension results in an amelioration of pulmonary hypertension that may allow surgical correction according to standard operating procedures of pulmonary hypertension units.

\section{References}

1. John Sutton MG, Tajik AJ, McGoon DC. Atrial septal defect in patients ages 60 years or older: operative results and long-term postoperative follow-up. Circulation. 1981;64:402-9.

2. Somerville J. How to manage the Eisenmenger syndrome. Int J Cardiol. 1998;63: 1-8.

3. Yamauchi H, Yamaki S, Fujii M, Iwaki H, Tanaka S. Reduction in recalcitrant pulmonary hypertension after operation for atrial septal defect. Ann Thorac Surg. 2001;72:905-6; discussion 906-7.

4. Yamauchi H, Yamaki S, Fujii M, Saji Y, Ochi M, Shimizu K. Atrial septal defect with borderline pulmonary vascular disease: surgery and long-term oral prostacyclin therapy for recalcitrant pulmonary hypertension. Jpn J Thorac Cardiovasc Surg. 2004;52:213-6.

5. Frost AE, Quinones MA, Zoghbi WA, Noon GP. Reversal of pulmonary hypertension and subsequent repair of atrial septal defect after treatment with continuous intravenous epoprostenol. J Heart Lung Transplant. 2005;24:501-3.

6. Barst RJ, McGoon M, Torbicki A, Sitbon O, Krowka MJ, Olschewski H, Gaine S. Diagnosis and differential assessment of pulmonary arterial hypertension. $J \mathrm{Am}$ Coll Cardiol. 2004;43:40S-7S. 